\title{
DOIS PRA LÁ E DOIS PRA CÁ: \\ AS POSSIBILIDADES DA DANÇA DE SALÃO NAS AULAS DE EDUCAÇÃO FÍSICA NO ENSINO MÉDIO'
}

\author{
Jamile Dal Cin \\ Universidade Comunitária da Região de Chapecó - Unochapecó, Santa Catarina, Chapecó, Brasil \\ Neusa Dendena Kleinubing \\ Universidade Comunitária da Região de Chapecó - Unochapecó, Santa Catarina, Chapecó, Brasil
}

\begin{abstract}
Resumo
Esta investigação teve por objetivo analisar as possibilidades de ensino-aprendizagem da dança de salão nas aulas de Educação Física no Ensino Médio a partir de uma proposta de intervenção realizada durante o estágio supervisionado. A pesquisa é de natureza qualitativa, sendo caracterizada pela pesquisa-ação. Os instrumentos utilizados para a coleta dos dados foram o plano de ação e o diário de campo, e para análise foi utilizada a técnica da análise temática (MINAYO, 2008). As situações e os dados encontrados no campo revelaram que, apesar do receio inicial, a dança de salão foi bem aceita pelos jovens. Eles afirmaram que foi interessante aprender algo diferente para além dos esportes, e que a dança é importante, pois oferece espaços para troca entre colegas e professores.
\end{abstract}

Palavras-chave: Dança. Educação Física. Ensino Médio.

\section{Introdução}

Já a algum tempo, discussões têm apresentado que a Educação Física (EF) nas escolas tem se caracterizado pelo trabalho, quase que exclusivo, das quatro modalidades de esportes coletivos mais populares no Brasil, como: vôlei, futebol, basquete e handebol. A inserção nos campos de estágio, no processo de formação inicial, também possibilitou confirmarmos esta situação, principalmente quando se trata dos anos finais do ensino fundamental e do ensino médio ${ }^{2}$.

Sabemos que a EF se constitui por um rol de conteúdos que vai muito além destas modalidades (incluindo-as). Além dos conteúdos tradicionais, dentre eles os esportes, há

\footnotetext{
${ }^{1} \mathrm{O}$ presente trabalho não contou com apoio financeiro de nenhuma natureza para sua realização.

${ }^{2}$ Deparamo-nos com esta situação quando realizamos nossos estágios nestes níveis de ensino, nos semestres de 2012-2 e 2013-1. Também isso era a realidade de nossos colegas em diferentes escolas e redes de ensino, tanto municipal, quanto estadual.
} 
inúmeros outros conteúdos que se agregam ao leque de conhecimentos que os alunos ${ }^{3}$ devem conhecer e vivenciar, incluindo aqueles que fazem parte da cultura local e regional.

Este texto trata de uma experiência que tivemos com a dança como conteúdo da Educação Física no Ensino Médio. Ao elaborarmos nosso planejamento de estágio curricular obrigatório, decidimos pela dança por entendermos que, na maioria das vezes, é "esquecida" pelos professores e somente lembrada, como apontam vários autores, em datas comemorativas ou como atividades extracurriculares (MARQUES, 2005; BRASILEIRO, 2003).

Com o objetivo de analisar as possibilidades de ensino-aprendizagem da dança de salão, propusemos um plano de intervenção para turmas do ensino médio, que foi desenvolvido durante nosso estágio supervisionado. Para Tortola e Lara (2009), esse conteúdo deve ser aprendido na escola porque proporciona a experimentação de diversas habilidades de movimento e formas de expressão e, principalmente, porque possibilita identificar a diversidade cultural.

Em nossas intervenções durante o estágio supervisionado, buscamos articular teoria e prática a fim de proporcionar uma experiência significativa aos alunos, bem como propusemos uma estrutura de aula na qual pudessem apresentar seus conhecimentos prévios dos estilos de dança de salão trabalhados. Essa estratégia foi fundamental para que fosse construído um ambiente favorável à aprendizagem, já que estabelecemos um espaço no qual a manifestação de saberes e dúvidas seriam acolhidas.

Na sequência do texto apresentamos a metodologia adotada neste estudo e a discussão dos resultados obtidos, sinalizando para as possibilidades de trabalho com este conteúdo no ensino médio e a importância de se tratar do estágio curricular obrigatório como espaço de pesquisa.

\section{Metodologia}

Este estudo de caráter qualitativo teve como base metodológica a pesquisa-ação. Thiollent (2007, p. 17) menciona que "na pesquisa-ação os pesquisadores desempenham um papel ativo no equacionamento dos problemas encontrados, no acompanhamento e na avaliação das ações desencadeadas em função do problema". Nesse pressuposto organizamos nossa intervenção que, desde o início (na fase do diagnóstico), considerou as ideias e os interesses dos alunos envolvidos neste estudo.

Os sujeitos que colaboraram com este trabalho foram os alunos das turmas 301 e 302 do ensino médio de uma escola da rede estadual de ensino da cidade de Chapecó - Santa Catarina, onde foi desenvolvida a docência da disciplina Estágio V do curso de licenciatura em EF da Universidade Comunitária da Região de Chapecó - Unochapecó. Ao longo do texto, a fim de preservar a identidade dos alunos que participaram desta pesquisa, usaremos letras seguidas de número para designar as falas dos meninos $(\mathrm{M})$ e meninas $(\mathrm{F})$.

Os instrumentos utilizados para a coleta dos dados foram: a) o plano de ação, composto por nove aulas, sendo que as danças de salão que fizeram parte do plano de ação -

\footnotetext{
${ }^{3}$ Neste texto usaremos a expressão "alunos" e "professores" quando estivermos discutindo de um modo geral e isto significa abarcar os gêneros masculino e feminino. Quando estivermos apresentando os dados faremos referência a meninos e meninas, conforme explicitamos na metodologia deste trabalho.
} 
danças gauchescas e tango - foram escolhidas pelos alunos durante os encontros nas monitorias realizadas anteriormente à docência da disciplina Estágio V, b) o diário de campo, no qual registramos os acontecimentos que surgiam durante nossa intervenção bem como as falas dos alunos. Ao final de cada aula tínhamos um tempo para falar sobre o que foi vivenciado e aprendido. Neste momento fazíamos os registros das falas e depois registrávamos os acontecimentos e situações surgidas na intervenção.

A análise dos dados foi orientada pela técnica da análise temática, que segundo Minayo (2008), consiste em desvendar os núcleos de sentidos que integram uma comunicação, "cuja presença ou freqüência signifiquem alguma coisa para o objeto analítico visado" (p. 316).

Neste texto optamos por apresentar a discussão de dois temas: a dança de salão como conteúdo possível nas aulas de educação física e o estágio curricular obrigatório como oportunidade de pesquisa como forma de qualificar a formação inicial.

\section{Resultados e Discussão \\ Dança de salão: um conteúdo possível nas aulas de Educação Física}

A dança de salão é bastante praticada por pessoas de todas as idades e gêneros, e oferecida em clubes recreativos, academias, aulas particulares, entre outros. Porém, quando falamos sobre dança no contexto escolar e conteúdo das aulas de EF, o conteúdo dança de salão é praticamente nulo.

A maioria dos professores e alunos vê a dança como espetáculo, pensando que nem todos podem praticá-la. Para que isso mude, Lopes e Teixeira (s/d) afirmam que ao trabalhar a dança de salão nas aulas de EF, é indispensável contextualizar esse tema para que os alunos se apropriem sobre seus conceitos, sua origem e os benefícios que esse conteúdo poderá proporcionar, pois assim serão capazes de analisar, refletir e opinar sobre esse conteúdo com propriedade.

A dança de salão sofreu muitas influências durante sua história, tanto sociais como culturais, e até deixou de ser popular durante certo período (PERNA, 2005). Segundo Almeida (2005), a dança de salão começou a fazer parte dos encontros da nobreza em seus salões. Inicialmente era denominada como danças sociais, sendo executada aos pares em bailes e reuniões, fazendo parte da educação da aristocracia diferenciando-se da classe menos favorecida, que praticava as danças folclóricas.

No Brasil, a dança de salão chegou em meados do século XVI com a vinda dos colonizadores portugueses e, posteriormente, com a dos colonizadores europeus (PERNA, 2005). Juntando as diferentes culturas e maneiras de dançar, incluindo as já existentes no Brasil como a cultura indígena e a dos negros africanos, foram formadas as danças típicas da cultura brasileira.

Nos últimos tempos, as mídias sociais têm ampliado os espaços de demonstrações da dança de salão. Em programas de televisão há concursos destinados à escolha do casal que tem o melhor desempenho em diferentes estilos, sendo que, muitos dos que se apresentam não sabiam dançar. Cada edição destes programas tem motivado muitas pessoas a procurarem aulas de dança em academias e clubes, incentivadas pela ideia de que a dança de salão pode 
ser praticada por todos ${ }^{4}$. Nisso nos perguntamos: seria necessária a aparição da dança na mídia para que as pessoas procurassem praticá-la? Ou, poderíamos pensar que se a dança fosse aprendida na escola, a vivência da prática nos momentos de lazer seria por um desejo pessoal e não por uma "moda" que surge de tempos em tempos.

Deste modo, não seria objetivo da EF oferecer práticas para que as pessoas possam, após encerrar sua educação básica, desenvolver com autonomia em seus momentos de lazer? Parece ser esta a questão que precisamos enfrentar com relação à dança e tantos outros conteúdos no contexto da EF escolar: "apreender" diferentes práticas para usufrui-las com autonomia em nossa vida cotidiana.

Assim, quando falamos sobre a dança de salão na escola como tema das aulas de EF, logo pensamos nas dificuldades para trabalhar esse conteúdo, seja por causa do espaço físico, da metodologia, planejamento e apropriação do conhecimento por parte do professor e, até mesmo, do preconceito formado de que dança é "coisa de menina".

Conforme as discussões de Kleinubing (2009), este preconceito parece ser mais da parte dos professores do que dos alunos, já que o que tem se encontrado é a boa aceitação ${ }^{5}$ dos alunos com o conteúdo dança, mostrando-se abertos a novas experiências e aprendizagens.

Um dos objetivos das intervenções que deram origem a este estudo foi o de identificar junto aos alunos as percepções que teriam com relação à prática da dança de salão. No primeiro contato com as turmas realizamos uma discussão sobre a dança como conteúdo da EF e os alunos argumentaram que já tiveram aulas de dança na escola, porém, como um projeto isolado, ministrado por outra professora e tendo como objetivo principal ensaiar para uma apresentação de encerramento do ano letivo, mas nunca tiveram dança como conteúdo das aulas.

Em um estudo realizado por Brasileiro (2003), alguns professores alegaram não trabalhar com dança na escola por causa do espaço físico, por ele ser limitado e a escola não possuir materiais necessários. A autora questiona o fato de que da mesma forma que o espaço é limitado para as aulas de dança, muitas vezes a quadra, onde são realizadas as aulas de EF, possui uma estrutura indesejada para a prática dos esportes e, mesmo assim, com as limitações, não deixa de ser conteúdo das aulas. Brasileiro questiona (2003, p. 49): "Não é mais fácil conseguir uma sala do que uma quadra, desde que a estrutura da sala seja menos exigente que a da quadra? E por que não ampliarmos nossa estrutura física para além da quadra, com salas de dança e ginástica?”. Em um estudo feito por Saraiva-Kunz (2003) a respeito da ausência da disciplina dança na escola, a autora chegou a conclusões parecidas

\footnotetext{
${ }^{4}$ Embora alguns artistas e celebridades que participam destes programas argumentem nunca terem dançado os diferentes estilos, temos noção de que o nível técnico e virtuosismo desenvolvidos se dão devido à dedicação de horas para o ensaio enquanto o programa está sendo apresentado, já que este tem caráter eliminatório, o que significa que "não é para todos". Enquanto isso, num contexto escolar e de lazer, não vemos a necessidade destas exigências, bem como dançar com sequências de passos pré-estabelecidos. De fato, o formato e a dança apresentada por estes programas não servem de modelos pedagógicos quando se visa a educação estética, porém não podemos negar o grande apelo motivacional que representam.

${ }^{5}$ Nos últimos tempos, realizamos diversas intervenções com a dança no contexto dos estágios supervisionados em diferentes níveis de ensino. Estas experiências nos têm mostrado que após a passagem do período de "desconfiança", isto é, a primeira e segunda aula, os alunos são muito receptivos a este conteúdo.
} 
com as citadas acima. Segundo a autora, os professores falam da necessidade de se ter, na escola, um local adequado para as aulas de dança e disponibilidade de recursos financeiros.

Em nosso estudo, encontramos o mesmo cenário descrito pelas autoras, pois a escola em que desenvolvemos o projeto não possuía espaço específico para aulas de dança, havia somente o ginásio. Este cenário não foi motivo para que não desenvolvêssemos o conteúdo. Nas aulas realizadas com a turma 301 não foi possível utilizar a quadra, já que havia outra turma com aulas de EF no mesmo horário. Então, com a ajuda dos alunos, em todas as aulas, abríamos um espaço empurrando as cadeiras e carteiras para o fundo e laterais da sala de aula, e assim realizamos as aulas de dança de salão. Em relação ao espaço, os alunos argumentaram que "Se tivesse um pouco mais de espaço ficaria mais fácil... Aqui a gente acaba se batendo, mas apesar do espaço físico pequeno foi possível fazer todos os passos". Já com a turma 302, tínhamos a possibilidade de utilizar o ginásio para as aulas, que foi muito aproveitado pelos alunos, já que usufruíram de todo o espaço da quadra sem se preocupar se iriam pisar nos pés dos colegas, como acontecia nas aulas da turma 301.

Na primeira aula realizada com a turma 302, quando perguntamos qual era a visão deles a respeito da dança como conteúdo da $\mathrm{EF}$, responderam em palavras soltas, como: movimento, ritmo, gestos que expressam coisas. A aluna F3 falou "A gente pode expressar sentimentos através da dança, se a gente tá feliz, triste, isso tudo pode ser mostrado". Na outra turma, 301, quando fizemos a mesma pergunta, a aluna F2 argumentou que "Ainda não tivemos esse conteúdo nas aulas de EF, mas deve ser bem melhor que ficar só jogando vôlei".

Esta última fala traz o alerta a respeito da prática repetitiva com relação aos conteúdos nas aulas, o que pode acabar ocasionando o desinteresse por parte dos alunos. Isso nos mostra que cabe ao professor a tarefa de pensar em conteúdos diversificados e estratégias de aula que possam proporcionar diferentes culturas corporais de movimento, dentre elas, a dança.

Fiamoncini (2003) fala sobre o ensino da dança na educação que aborde a criatividade, expressividade e a expressão pelo movimento, e conclui dizendo que "devemos assumir o compromisso de buscar alternativas, estratégias para uma educação transformadora, emancipatória, que seja mais criativa, expressiva e sensível" (p. 62).

Marques (2012) fala sobre o repertório da dança na escola, afirmando que na maioria das vezes, ela é trabalhada "de forma mecânica, superficial, acrítica, por meio de cópia e reprodução de sequências de passos preestabelecidas" (p. 17) e afirma que dessa maneira o professor não contribui para a educação efetiva dos alunos.

O processo de ensino-aprendizagem da dança na escola deve-se compor da linguagem artística da dança, para que os alunos possam compreender e apreciá-la de forma crítica, consciente e com significados, e isso é possível quando se conhece os elementos da linguagem. Marques (2012) argumenta que o conhecimento da linguagem e de seus elementos, tais como o corpo, o espaço, as qualidades de movimento, entre outros, são necessários para que os apreciadores da dança compreendam melhor os repertórios dançados, não sendo esses conhecimentos prerrogativa somente dos artistas/dançarinos. Nesse sentido, a dança no ambiente escolar é o lugar criado para os alunos atuarem, interagirem e modificarem sua dança, buscando a construção subjetiva, em relação aos demais colegas e orientados pelo professor (DUARTE, 2007).

Às vezes, a construção de um espaço/tempo que privilegie o protagonismo dos alunos no processo de fazer dança não é tarefa fácil. A desconfiança inicial, o receio de realizar os movimentos e o medo do julgamento dos colegas são barreiras que precisam ser ultrapassadas e, neste momento, a mediação do professor é de fundamental importância. 
No início da nossa intervenção com a turma 301, os alunos se mostravam tímidos e apresentaram resistência para as atividades, porém com o decorrer das aulas foi possível perceber o envolvimento dos alunos, e eles também perceberam mudança em seus comportamentos, como percebemos no comentário do aluno M8: "No início a gente teve uma resistência por causa da timidez, e agora a gente se solta para dançar e não tem medo de pagar mico, ou que os outros deem risada de nós", e seus colegas M2 e M6, sobre as aulas de tango, complementaram: "Essa está sendo a dança mais difícil até agora, mas com a ajuda da professora, e com a gente se ajudando fica mais fácil. Vamos sair daqui quase um tanguero!". Vários alunos comentaram como a turma estava interagindo e participando das aulas, e também conversando mais uns com os outros, como colegas. O aluno M2 disse que "As pessoas estão se envolvendo mais, o que torna as aulas cada vez mais divertidas". Sua colega F2 argumentou: "Apesar da resistência que tivemos logo nas primeiras aulas, por ser dança de salão, é um conteúdo muito bom, pois há interação no grupo, principalmente entre meninas e meninos, ajuda na timidez, e não é impossível de ser trabalhado".

Também com a turma 302, apesar da resistência do início, pode-se perceber a motivação para as aulas, e isso os alunos acabaram por perceber também, e comentaram: "Essas danças fazem a gente ter mais atitude, e está me ajudando ainda mais, pois sou tímida. Temos mais contato entre nós e estamos interagindo mais" (Aluna F9). E os meninos, principalmente, comentaram que "Não há mais aquela individualidade que existia antes de quem é o melhor". Na quarta aula, o aluno M3 disse: "A turma está bem entrosada, e não tem mais aquela resistência que tiveram no primeiro dia, hoje nós chegamos já querendo dançar, só esperando a professora começar a aula". A aluna F4 comentou a respeito de como ela estava conversando mais com seus colegas, falando: "Com essas aulas ocorreu um entrosamento entre os colegas, há mais comunicação, tanto nas aulas de EF quanto nas outras também". Assim, podemos concluir que para estes alunos as aulas de dança colaboraram para que eles se aproximassem entre si e construíssem outras formas de se relacionar, possibilitando "diferentes formas de estar-com-os-outros, geradoras de outras percepções com relação ao entorno" (KLEINUBING, 2009, p. 98).

Refletindo a partir destes dados, não há como não pensar no aparato teórico que a educação estética nos oferece para refletir sobre a tão necessária educação "sensível" dos sujeitos. Conduzir a prática pedagógica a partir dos pressupostos da educação estética ${ }^{6}$ pode possibilitar aos alunos "construir um "olhar' diferenciado para e sobre o mundo" (KLEINUBING, 2009, p. 59). Linhares (2003) fala sobre como a educação estética pode trabalhar com esse olhar diferenciado, começando pelos professores a olhar se desabituando do que é considerado comum e normal, para olhar de outro modo, construindo e desconstruindo os fatos comuns de uma cultura?

Saraiva-Kunz (2003) argumenta que na dança se constitui uma forma de ser-estar no mundo diferente daquela forma de ser-estar no cotidiano, onde "o Eu pode ser vivenciado em

\footnotetext{
${ }^{6}$ Neste espaço não será possível desenvolvermos de forma mais profunda esta discussão, porém é importante salientar que nossos estudos estão fundamentados, principalmente, nos trabalhos de Saraiva-Kunz (2003), Saraiva (2009; 2012), Linhares (2003) e Galeffi (2007).

${ }^{7}$ Somente como exemplo, poderíamos pensar como se construiu a ideia de que a dança é "coisa de menina" ou a de que os meninos não querem dançar. Se os professores questionassem como e por que esta ideia foi culturalmente construída, talvez a dança se tornasse um conteúdo mais frequente nas aulas.
} 
diferenciadas localizações corporais, ampliando-se no espaço; a pessoa não é mais objeto do meio exterior, que se possa observar, manipular, mas sim vivencia o ser agora e a própria sensibilidade" (p. 109).

Dessa citação compreende-se que, ao dançar, o sujeito pode vivenciar uma nova forma de ser,construindo, pelos movimentos de dança, novas sensibilidades tanto em relação a si mesmo quanto aos outros. Também ao dançar, se mediados pelos entendimentos da educação estética, os sujeitos são capazes de realizar leituras diferenciadas do mundo, já que nesta perspectiva "as sensibilidades" são ampliadas: ver, ouvir, tocar e sentir o outro na dança nos impõe a necessidade de construção de outros referenciais, diferentes daqueles impostos pela mídia, por exemplo.

Refletindo sobre esses entendimentos parece que ainda falta, por parte dos professores, interesse em elaborar um projeto que possa vir a inserir a dança na escola como conteúdo da $\mathrm{EF}$ e perceber que, a partir de processos que exigem criatividade, expressividade e sensibilidade - elementos da arte - poderemos oportunizar ao aluno a possibilidade de se expressar, de criar, sentir e perceber o mundo que está a sua volta. $\mathrm{Na}$ última aula, quando foi realizada a reflexão final, a fala mais marcante foi a do aluno M3 quando disse: "Gostaria que a dança fosse um tema obrigatório da EF". Essa fala vem ao encontro dos achados de Kleinubing (2009, p. 105) em seus estudos, quando afirma que "os jovens percebem, 'sentem' as contribuições das atividades expressivas no processo de formação, ou mesmo, nas relações estabelecidas no cotidiano com seus pares ou professores".

Analisando nosso processo de intervenção podemos assegurar que, apesar de toda a resistência apresentada pelos alunos no início das aulas de dança de salão, houve grande envolvimento destes e podemos conferir pelas falas, o quanto gostaram de ter vivenciado a dança de salão como um conteúdo nas aulas de EF. A aluna F5 comentou "Ótima aula, e uma boa iniciativa para aprendermos coisas novas na escola", e sua colega F9 completou "É mesmo uma boa iniciativa, único jeito de vermos coisas novas". Os meninos também falaram sobre as aulas de dança, argumentando: "Dançar também faz parte das aulas de EF" e "Esse é um bom tema para se trabalhar nas aulas, pois nos mexemos bem mais do que ficar somente jogando vôlei".

Os dados desta pesquisa-ação nos levam a pensar sobre a quantidade de experiências significativas que estamos deixando de oferecer aos alunos e que não podemos continuar repetindo as mesmas desculpas. Há espaço e desejo, por parte dos alunos, para que a dança "tome (o) corpo" nas escolas, e poderíamos começar pelas aulas de Educação Física: dois pra lá e dois pra cá, poderia ser o passo inicial!

\section{Estágio curricular obrigatório: relações entre teoria, prática e pesquisa}

O componente "estágio curricular obrigatório", inserido nas matrizes dos cursos de licenciatura tem o papel de inserir o estudante no cotidiano da escola, espaço no qual, deixará suas marcas como professor, a partir das suas intervenções pedagógicas. Com as constantes mudanças na legislação, o estágio deixou de ser a parte final da formação, momento no qual "se deveria mostrar na prática o que se aprendeu na teoria" para ser o que entendemos como o eixo central da formação, já que hoje deve estar presente na formação desde o início da segunda metade do curso. Essa configuração exige uma mudança de pensamento entre teoria e prática, como explicitam Pimenta e Lima (2004, p.43): 
O papel das teorias é iluminar e oferecer instrumentos e esquemas para análise e investigação que permitam questionar as práticas institucionalizadas e as ações dos sujeitos e, ao mesmo tempo, colocar elas próprias em questionamentos, uma vez que as teorias são explicações provisórias da realidade.

Neste processo de intervenção e pesquisa com dança de salão no ensino médio pode-se fazer uma relação direta entre a teoria e a prática. Este conteúdo aprendido na formação inicial transformou-se em objeto de conhecimento para os alunos do ensino médio e, como objeto de conhecimento, tem suas faces teórica e prática que devem ser consideradas. $\mathrm{O}$ desafio para a intervenção docente é pensar na articulação entre teoria e prática de forma que os alunos se sintam instigados, entre equilíbrios e desequilíbrios, a seguir os caminhos do (re)aprender.

Em todas as aulas tínhamos como objetivo articular teoria e prática buscando sempre a melhor forma de proporcionar aos alunos aprendizado sobre o conteúdo que seria abordado, conversando e ajudando-os em suas dificuldades, e tentando proporcionar um espaço no qual eles se sentissem dispostos a realizar as atividades sem se preocupar com opiniões e/ou preconceitos alheios. Nas reflexões finais de cada aula isso apareceu nas falas: F11 diz: "A professora ajuda bastante a gente, passa de par em par para ajudar nos movimentos, corrigir o que está errado e dá bastante atenção, assim a gente aprende do jeito certo, não de qualquer jeito", e sua colega F5 completa: "A professora dá atenção separadamente, nos corrige e nos ajuda nos movimentos, é bom assim".

Com essa articulação entre teoria e prática realizada no estágio supervisionado foi possível ter uma aproximação com a realidade no contexto escolar, proporcionando uma nova reflexão sobre a escola e a área de atuação e, principalmente, ressignificar a visão de que o estágio é a parte "prática" do curso.

Com a aproximação à realidade é possível permitir uma ampliação do entendimento em relação ao estágio. Uma das possibilidades é implementar a pesquisa também como estratégia pedagógica na formação de futuros professores. Sobre isso, Pimenta e Lima (2004, p. 46) afirmam que a pesquisa no estágio se traduz "na possibilidade de os estagiários desenvolverem postura e habilidades de pesquisador a partir das situações de estágio, elaborando projetos que lhes permitam ao mesmo tempo compreender e problematizar as situações que observam."

Em nosso caso, a partir da pesquisa-ação pudemos ampliar a visão sobre o contexto escolar, pensando nas aulas como um processo de construção de saberes relacionado à dança, por exemplo, seus elementos técnicos, históricos e sociais. Para inserir a dança de salão foi preciso elaborar um projeto que pudesse atender as expectativas dos alunos e reflexões realizadas em aula, pensando também em solucionar impasses observados durante as monitorias, como por exemplo, a individualidade. Também foi possível aos alunos construir outros referenciais sobre a Educação Física, percebendo-a como área de conhecimento que vai muito além das quadras de futsal e vôlei.

Acreditamos que a pesquisa no contexto do estágio pode expandir a ideia sobre o ser professor, refletindo e analisando as aulas como forma de construção de conhecimento, problematizando com os alunos de forma crítica a respeito dos conteúdos trabalhados (no nosso caso, a dança de salão, muitas vezes esquecida pelos docentes). Em nosso entendimento, uma questão bastante importante durante este tempo de intervenção foi a 
manutenção de um caráter investigativo e avaliativo que provocaram mudanças no decorrer do processo para melhor aprendizado dos alunos. Pensamos que nisso deve se sustentar a prática pedagógica do professor. Acreditamos que esta forma de realizar o estágio de docência, incorporando a pesquisa, possibilita aos estudantes se tornarem pessoas que valorizam a prática profissional, pois buscam intervir na realidade para, além de solucionar problemas, elaborar projetos para ampliar a visão dos alunos a respeito dos saberes que devem ser construídos com a disciplina de Educação Física.

Ghedin (2007) afirma que é papel das universidades pensar na formação de um estudante que além de professor, se volte e estude os problemas que afetam a educação na interface social, e exigir dos alunos uma postura investigativa, na qual o conhecimento possa ser produzido de forma crítica, competente e criativa. Argumenta que a pesquisa no estágio pode ser o caminho certo para se pensar na construção da identidade profissional do futuro professor, afirmando que o docente se torna competente na medida em que pesquisa: "ele alia a docência à pesquisa como forma de articular a teoria-prática como forma de expressar sua competência técnica e seu compromisso político com a práxis de professorar" (GHEDIN, 2007, p. 03).

A partir das reflexões realizadas neste texto, podemos inferir que a articulação entre teoria e prática e a pesquisa no estágio curricular obrigatório possibilita ao estudante vivências e conhecimentos fundamentais no seu processo de formação. No nosso caso, utilizar da pesquisa no estágio proporcionou uma visão de pesquisadoras, problematizando, implementando, avaliando e elaborando projetos para intervir no contexto escolar. Utilizar-se dos saberes adquiridos durante a graduação para planejar um processo de ensinoaprendizagem no contexto escolar nos obriga a pensar nas transposições necessárias que esta situação exige, pois nem sempre a forma como é desenvolvida na graduação é possível de ser trabalhada na escola, já que os sujeitos e a cultura são outros, e as relações estabelecidas com este conteúdo também.

Nesse sentido, aprendemos que a intervenção pedagógica não é algo determinado, ou seja, nem sempre acontecerá conforme previsto, e nisto o caminho trilhado pela pesquisa-ação trouxe indicativos importantes: planejar, implementar e avaliar o processo, sempre pensando em ações que motivem os alunos à participação, instigando-os a vivenciarem diferentes práticas corporais nas aulas de EF.

\section{Considerações Finais}

Nesta pesquisa-ação, a partir das intervenções, pode-se identificar um contexto em que a dança não fazia parte das aulas de EF, e que o conhecimento sobre este conteúdo era mínimo. Apesar de a escola não dispor de espaço físico para a realização das aulas de dança de salão e da resistência apresentada pela maioria dos alunos no início da intervenção, não foi motivo para que este conteúdo não fosse trabalhado.

Com esta pesquisa realizada durante o estágio supervisionado foi possível articular a teoria e prática vista durante a formação com a teoria e prática durante as aulas na escola, não repassando os conteúdos vistos na graduação, mas transformando-os durante o processo, buscando planejar as aulas de uma maneira que os alunos se sentissem motivados a construir conhecimentos relacionados à dança de salão.

Vemos que essa relação entre teoria e prática e a pesquisa no estágio proporcionou uma vasta visão em relação ao contexto escolar na forma como planejar as aulas levando em 
consideração o local onde estávamos estagiando e os alunos, produzindo conhecimentos de forma crítica, mantendo um caráter investigativo e avaliativo durante toda a intervenção para melhor aprendizado por parte dos alunos.

Os dados coletados possibilitaram pensar que o conteúdo dança de salão apresenta muitas possibilidades de ensino-aprendizagem. Para além disto, pensamos que a dança como conteúdo da EF tem uma maior amplitude no processo de formação humana ao trabalhar a linguagem corporal, a história da dança e das danças de salão nas suas diferentes manifestações culturais. Ao nos depararmos com os preceitos da educação estética também visualizamos o trabalho com a dança como um espaço/tempo capaz de promover o respeito pelo outro e pelas diferentes formas de ser e estar no mundo, como aponta Saraiva-Kunz (2003). Nesta pesquisa identificamos a dança de salão como conteúdo que oportuniza aos jovens um espaço/tempo de trocas e compartilhamentos de "seres" e saberes, contribuindo para a formação de sujeitos que compreendem melhor a si mesmos e aos outros.

\title{
TWO TIMES TO THE LEFT TWO TIMES TO THE RIGHT: THE POSSIBILITIES OF BALLROOM DANCING LESSONS IN PHYSICAL EDUCATION IN HIGH SCHOOL
}

\begin{abstract}
This research aimed to examine the possibilities for teaching and learning ballroom dance in physical education classes in high school from a proposed intervention during supervised training. The nature of this research is qualitative, characterized by action research. The instruments used for data collection were a plan of action and a field diary, and to analyze was used the technique of thematic analysis (MINAYO, 2008). The situations and the data found in the field revealed that, despite the initial fear, ballroom dancing was well accepted by the young students. They stated that it was interesting to learn something different apart from sports, and that dancing is important because it provides spaces for exchange between classmates and teachers.
\end{abstract}

Keywords: Dancing. Physical Education. High School.

\section{DOS PARA AQUÍ Y DOS POR AHÍ: LAS POSIBILIDADES DE EL BAILE DE SALÓN EN LAS CLASES DE EDUCACIÓN FÍSICA EN LA EDUCACIÓN SECUNDARIA}

\section{Resumen}

Esta investigación tuvo como objetivo analizar las posibilidades de enseñanza y aprendizaje de baile de salón en clases de Educación Física en la escuela secundaria a partir de una propuesta de intervención realizada durante las prácticas. La investigación es de naturaleza cualitativa, siendo caracterizada por la investigación-acción. Los instrumentos para recolección de datos fueron el plan de acción y el diario de campo, y analizar se utilizó la técnica de análisis temático (MINAYO, 2008). Las situaciones y los datos encontrados en el campo revelaron que, a pesar del temor inicial, el baile de salón fue bien aceptado por los jóvenes. Ellos afirmaron que fue interesante para aprender algo diferente, además de los deportes, y que la danza es importante porque proporciona espacios para intercambio entre sus compañeros y profesores.

Palabras clave: Danza. Educación Física. Educación secundaria.

\section{Referências}

ALMEIDA, C.M. de. Um olhar sobre a prática da dança de salão. Movimento e Percepção. 
Espírito Santo de Pinhal - SP, v. 5, n. 6, p. 129-134, jan./jun., 2005.

BRASILEIRO, L. T. O conteúdo "dança" em aulas de Educação Física: temos o que ensinar? Revista Pensar a Prática. Goiás. v. 6, n. 1, p. 45-58 jul./jun., 2003.

DUARTE, G. de O. O dançar na Educação Física escolar: a experiência estética no movimento humano. Revista Educação. Santa Maria. v. 32, n. 1, jan./jul., 2007.

FIAMONCINI, L. Dança na Educação: a busca de elementos na arte e na estética. Revista Pensar a Prática. Goiás. v. 6, n. 1, p. 59-72 jul./jun., 2003.

GALEFFI, D. A. Educação estética com atitude sensível transdisciplinar: o aprender a ser o que se é propriamente. Revista Em Aberto, Brasília, v. 21, n.77 jun/2007, p. 97-111. Disponível em:

<http://www.emaberto.inep.gov.br/index.php/emaberto/article/viewFile/1168/1067> Acesso: 16 set. 2007.

GHEDIN, E. Estágio, pesquisa e a produção do conhecimento na formação de professores (as).In: II ENCONTRO ESTADUTAL DE DIÁTICA E PTRÁTICA DE ENSINO, 2007, Goiás, Anais...Goiás: CEPED, 2007, v.1, p. 1-13.

KLEINUBING, N. D.A dança como espaço-tempo de intersubjetividades: possibilidade da educação física no ensino médio. 2009. 137 f. Dissertação (Mestrado em Educação Física) - Centro de Desportos, Universidade Federal de Santa Catarina, Florianópolis, 2009.

LINHARES, Â. M. B. O tortuoso e doce caminho da sensibilidade: um estudo sobre arte e educação. 2 ed. Ijuí: Unijuí, 2003.

LOPES, M. D.; TEIXEIRA, D. A Dança de Salão na Educação Física: uma implementação prática na perspectiva da pedagogia histório-crítica. s/ ano. Disponível em:

<http://www.diaadiaeducacao.pr.gov.br/portals/pde/arquivos/2149-8.pdf $>$. Acesso em: 15 set. 2012.

MARQUES, I. Dançando na escola. 2 ed. São Pauo: Cortez. 2005.

MARQUES, I. Linguagem da Dança: arte e ensino. In: MENDONÇA, R. H. Salto para o Futuro. Rio de Janeiro: Equipe do Núcleo de Produção Gráfica de Mídia Impressa - TV Brasil, 2012. p. 16-21.

MANFIO, J. B.; PAIM, M. C. C.. A dança no contexto escolar da Educação Física: percepção de professores de ensino médio. Revista Digital. Buenos Aires. v. 13, n. 125, out. 2008.

Disponível em: <http://www.efdeportes.com/efd125/a-danca-no-contexto-da-educacao-fisicaescolar.htm>. Acesso em: 22 ago. 2012.

MINAYO, M. C. de S. O Desafio do Conhecimento: pesquisa qualitativa em saúde. São 
Paulo: Hucitec, 2008.

PIMENTA, S. G.; LIMA, M. S. L. Estágio e Docência. São Paulo: Cortez, 2004.

PERNA, M. A. Samba de gafieira: a história da dança de salão brasileira. Rio de Janeiro: O Autor, 2001.

SARAIVA, M. do C. Elementos para uma concepção do ensino de dança na escola: a perspectiva da educação estética. Revista Brasileira de Ciências do Esporte, Campinas, v.30, n.3, p. 157-171, maio 2009.

SARAIVA. M. do C. Educação estética: o prólogo da dança-arte-educação. Uma leitura em Schiller, Adorno e Marcuse. In: SARAIVA, M. do C.; KLEINUBING, N.D. Dança: diversidade, caminhos e encontros. Jundiaí: Paco Editorial, 2012.

SARAIVA-KUNZ, M. do C.. Dança e Gênero na Escola: formas de ser e viver mediadas pela educação estética. 2003. 411 f. Tese (Doutorado em Motricidade Humana na Especialidade Dança) - Faculdade de Motricidade Humana, Universidade Técnica de Lisboa, Lisboa, 2003.

TORTOLA, E. R.; LARA, L. Mi. A dança de salão no contexto escolar: aspectos da pluralidade cultural. Revista Digital. Buenos Aires. v. 14, n. 133, jun. 2009. Disponível em: $<$ http://www.efdeportes.com/efd133/a-danca-de-salao-no-contexto-escolar.htm $>$. Acesso em: 22 ago.2012.

THIOLlENT, M. Metodologia da Pesquisa-ação. São Paulo: Cortez, 2007.

Recebido em: 26/03/2014

Revisado em: 29/01/2015

Aprovado em: 11/08/2015

Endereço para correspondência: jamiledalcin@unochapeco.edu.br

Jamile Dal Cin

Universidade Comunitária da Região de Chapecó

Avenida Senador Attilio Fontana - E - 591

Efapi

89809-000 - Chapecó, SC - Brasil - Caixa-postal: 1141 